\title{
É para Menino ou para Menina? Representações de Masculinidade e Feminilidade
}

\author{
Is It for Boys or Girls? Representations of Maleness and Femaleness
}

\section{¿Es para un Niño o una Niña? Representaciones de Masculinidad y Feminidad}

\author{
Elisângela Domingues Michelatto Natt \\ Universidade Federal de Minas Gerais, Brasil \\ elisdomingues@gmail.com
}

\author{
Alexandre de Pádua Carrieri \\ Universidade Federal de Minas Gerais, Brasil \\ alexandre@face.ufmg.br
}

\section{Resumo}

Buscamos compreender as representações criadas e disseminadas pela mídia de negócios, se não estimulando, então contaminando, as práticas de homens e mulheres no âmbito organizacional. Analisamos oito revistas de circulação periódica que remetem ao estereótipo do homem e da mulher de negócios. Os exemplares foram das revistas Exame, IstoÉ Dinheiro, Época Negócios, Pequenas Empresas \& Grandes Negócios, Cláudia, Marie Claire, VIP e Playboy. Para a análise, recorremos à Semiótica, ciência que se ocupa em estudar os signos, tratando as possibilidades sígnicas de formas de linguagem verbais ou não. Constatamos que a divisão da cena social entre masculino e feminino nas representações difundidas pelas revistas estimulam e retificam as práticas sociais, num movimento vicioso, em que o leitor segue consumindo o conteúdo dessas revistas, corroborando as crenças já arraigadas na sociedade.

Palavras-Chave: Gênero; Mídia; Negócios.

\begin{abstract}
We seek to understand the representations created and disseminated by the business media, that contaminate, if not encourage, the practices of men and women in organizational context. We analyzed eight periodic magazines referring to the stereotype of business men and women. The samples were copies of the Brazilian magazines Exame, IstoÉ Dinheiro, Época Negócios, Pequenas Empresas \& Grandes Negócios, Cláudia, Marie Claire, VIP and Playboy. Our analysis was based on Semiotics, the science concerned to the study of signs, which treats on the signifying possibilities of the several forms of language, whether verbal or not. We note that the division of the social scenery between masculine and feminine roles in the representations disseminated by the media stimulates and reifies social practices, as in a vicious circle, in which the reader follows consuming the contents of these magazines, that confirm beliefs already entrenched in the society.
\end{abstract}

Keywords: Gender; Media; Business.

\section{Resumen}

Buscamos entender las representaciones creadas y difundidas por los medios de comunicación de negocios, que si no estimulan, contaminan las prácticas de hombres y mujeres en el ámbito de las organizaciones. Analizamos 8 revistas de circulación periódicas que hacen referencia al estereotipo 
del hombre y la mujer de negocios. Las muestras son las revistas Exame, IstoÉ Dinheiro, Época Negócios, Pequenas Empresas \& Grandes Negócios, Cláudia, Marie Claire, VIP y Play Boy. Para el análisis se utilizó la Semiótica, ciencia que se ocupa de estudiar los signos, tratando las posibilidades sígnicas de formas de lenguaje verbal o no verbal. Constatamos que la división de la escena social entre lo masculino y lo femenino en las representaciones difundidas por las revistas estimula y reifica las prácticas sociales en un movimiento vicioso en el que el lector sigue consumiendo el contenido de estas revistas, lo que confirma las creencias ya arraigadas en la sociedad.

Palabras-Clave: Género; Medios de Comunicación; Negocios.

\section{Masculinidades e Feminilidades}

Por que as práticas discriminatórias são tão decorrentes? Por que, mesmo em sociedades consideradas evoluídas, ainda se constatam tantas situações de violência simbólica ou não - contra as mulheres e também contra os homens que não se enquadram nos estereótipos impingidos ao sexo masculino? Certamente não poderíamos apontar um único motivo, mas uma série de retificações de crenças e valores distorcidos que continuam assombrando nossa realidade. As práticas violentas empreitadas contra mulheres e homossexuais estão arraigadas em circunstâncias históricas e requerem uma breve discussão para que se torne possível compreender os fundamentos do preconceito e da equivocada naturalização dos papeis atribuídos a homens e mulheres.

Nos mais variados ambientes, aquilo que é feminino ou que remete a uma forma de feminilidade acarreta em julgamento e mesmo em segregação. Nas famílias e nas organizações ainda predomina o modelo masculino, no qual cabe à mulher, o papel de servir e obedecer. Contudo, as mulheres vêm aumentando sua participação no mercado de trabalho (CARRIERI et al, 2013a) e, principalmente nas comunidades mais pobres, vêm assumindo o posto de chefe de família. Por que então, ainda há tantas desigualdades no mercado de trabalho e mesmo em relação às posições políticas e sociais? A questão é que ainda são partilhados socialmente, os ideais e estereótipos de masculinidade e feminilidade. Esses ideais, no entanto, estão imbricados nas práticas sociais e decorrem de significativos eventos partilhados na contemporaneidade. A forma de patriarcado, discutida por Pateman (1993), é fundada na divisão estabelecida entre os espaços públicos e privados, sendo o primeiro o lugar para as tomadas de decisão e de poder e o segundo o lugar para as paixões, estando permitido às mulheres apenas o terreno domestico, considerado incivilizado.

Embora pareça lugar comum relacionar as diferenças entre homens e mulheres às questões biológicas, é preciso nos desprender de tais diferenças para que seja possível compreender as verdadeiras implicações envolvidas em torno da diferença social. Não queremos, contudo, contestar as diferenças biológicas, mas faz parte de nossa empreitada demonstrar como essas diferenças não são as responsáveis pelo estabelecimento de desigualdades sociais entre os gêneros. Para Louro (1997) não são essas diferenças fisiológicas que fazem com que homens e mulheres sejam destinados a cumprirem papéis que lhes são designados a partir do sexo. A ocupação dos espaços sociais e a divisão desse espaço entre feminino e masculino são decorrentes das representações e valoração sociais (ECCEL; GRISCI, 2011; ECCEL et al, 2010). A partir 
dessas representações e da valorização de características não inerentes ao sexo, se determinam, equivocadamente, os lugares e posições a serem ocupados por homens ou mulheres nas mais variadas organizações sociais (CARRIERI et al, 2013b; DINIZ et al, 2013; MENEZES et al, 2013).

No intuito de compreender como as representações de masculinidades perpassam a realidade social, a partir de representações criadas e disseminadas pela mídia de negócios, se não estimulando, então contaminando, as práticas de homens e mulheres no âmbito organizacional, foram analisadas 8 revistas de circulação periódica e de acesso popular, que remetem ao estereótipo do homem e da mulher de negócios. Os exemplares selecionados foram das revistas Exame, IstoÉ Dinheiro, Época Negócios, Pequenas Empresas \& Grandes Negócios, Cláudia, Marie Claire, VIP e Playboy.

A partir da análise desse material foi possível traçar um perfil esperado para homens e mulheres que atuam no ambiente empresarial. $\mathrm{O}$ material possibilitou que desvelássemos o ideal de masculinidade imbricado na representação que tais revistas buscam construir ou perpetuar entre homens e mulheres e, entre a sociedade de forma geral. Foram muitos os elementos evidenciados que denotam a necessidade de um perfil pautado na virilidade para que se obtenha sucesso no mundo dos negócios. As revistas parecem delinear quem tem o direito e o dever de ocupar esse ou aquele cargo. Questões como a aparência são claramente definidas dentro de um estereótipo pautado no masculino, não importando quem representa o executivo nas capas das revistas. Parece haver um consenso entre a mídia de negócios de que o mundo dos negócios deve ser masculino por excelência.

A administração é masculina. É o que apontam os estudos de Eccel et al (2010),
Eccel e Grisci (2011), Carrieri et al (2013), Diniz et al (2013) e Menezes et al (2013). É ainda o que mostram as revistas destinadas ao público que atua ou pretende atuar frente a uma respeitada organização. Mas afinal, o que significam tais representações? Não seriam esses estereótipos apenas um prolongamento da vida socialmente constituída? Haveria um perfil patriarcal que assola as organizações e define que o lugar das mulheres é na cozinha? Na tentativa de refletir acerca dessas questões desenvolveremos uma discussão que se baseou não apenas no material coletado, mas também nos materiais construídos por autores que se debruçam sobre as questões de gênero, tentando evidenciar o quanto as diferenças entre o masculino e o feminino estão imbricadas em construções ideológicas. Essas diferenças que perpassam a sociedade acabam por delinear condições que delimitam as ações e posições adotadas por homens e mulheres (HASSARD et al, 2000). Assim, criam-se situações que cerceiam os indivíduos que não se enquadram nos estereótipos estabelecidos pela classe dominante. Os arranjos que se estabeleceram historicamente (BOURDIEU, 2007) não permitem a aceitação de um contínuo entre o mais masculino e o mais feminino. Esses padrões radicais e intrinsecamente opostos, acabam por marginalizar os que se encontram em outra parte desse contínuo.

Nesse sentido, entendemos o conjunto de corpos generificados como uma construção e resultado de uma interpretação política e cultural dos corpos biologicamente estabelecidos. Partindo desses pressupostos e de que o corpo é mais do que o depositário das marcas de gênero, compreendemos que o corpo ultrapassa as características superficiais e seguem marcados por seu caráter singular e dinâmico, sendo construídos de forma contingencial à cultura e às dinâmicas sociais. A partir dessa 
construção, e no intuito de clarificar nossa empreitada, buscamos organizar esse artigo de forma a proporcionar o melhor entendimento acerca das questões exploradas. Desta forma, foram organizadas seis seções. Após essa introdução, exploraremos mais detalhadamente as questões envolvendo o tema gênero. Posteriormente, apresentaremos o percurso metodológico e em seguida, o material coletado e os detalhes da investigação. Por fim, serão apresentadas nossas análises e conclusões sobre a pesquisa.

\section{Gênero}

Os gêneros são constituídos nas relações sociais (LOURO, 1997; BUTLER, 2010) e deveriam ser compreendidos a partir de uma perspectiva que proporcionasse uma contraposição ao binarismo sexual, evitando que se definissem homens e mulheres a partir de polos distintos, e que fosse capaz de considerar o relacionamento entre esses extremos. É de suma importância que se compreenda que homens e mulheres podem ter características tanto femininas quanto masculinas. Ambos podem adotar posturas consideradas inerentes ao outro sexo. Scott (1995) propõe uma problematização interessante, em que homens e mulheres devem ser entendidos como conceitos que representam categorias vazias, sem significados definitivos e, embora fixadas, apresentam alternativas, que tendem a ser negadas e reprimidas. Nesse sentido, as identidades de gênero, sempre em permanente processo de construção, são pautadas em afirmativas e práticas que nos posicionam na esfera social, a partir de crenças que remetem ao ideal de masculinidade (DINIZ et al, 2013). Nas discussões apresentadas por Matos (2000a; 2000b; 2001b), a construção das identidades de gênero é compreendida como resultado de processos dinâmicos de estilização de gênero, em que um conjunto de comportamentos se repete, reproduzindo ou contestando estruturas que regulam as demarcações de gênero em um dado espaço e tempo (ECCEL et al, 2010).

Os papéis e a atuação dos sujeitos costumam ser adotados com base nas experiências sociais, tanto das ações quanto do próprio corpo, construindo as identidades de gênero (BOURDIEU, 2007), que abarcam uma dimensão ética e estética, em que a articulação das práticas sociais é relativa ao gênero, e fazem emergir possibilidades de ruptura com os padrões estereotipados (MATOS, 2000b). Contudo, Oliveira (2004) e Butler (2006) apontam uma tendência ao comodismo social que leva os indivíduos a adotarem comportamentos que reafirmam a continuidade e conformidade com a tradição, retificando padrões estruturados historicamente. No entanto, Eccel et al (2010) apontam outro fator importante à compreensão das questões de gênero, o fato de que o corpo foi sendo objeto de estudos das ciências naturais, humanas e sociais e, atualmente compõe ainda, alguns estudos sobre cultura. A partir do trabalho das autoras, observa-se que, desde a Grécia até os dias atuais, o culto do corpo passou por diversas transformações, tanto sociais quanto psíquicas.

Foi a ascensão do capitalismo que culminou na valorização do individualismo, fazendo emergir um novo padrão corporal. Novos padrões e saberes são então empreendidos, e o corpo passa a ser considerado uma posse e não uma possibilidade de ser. Em outras palavras, o corpo vai sendo aperfeiçoado e disciplinado, possibilitando novas formas de poder mantidas por padrões corporais estereotipados. Marcas infringidas ao corpo, como o caso do gênero e das etnias, acabam por constituir indicativos sociais, que ao 
serem observados podem remeter às identidades e também operar jogos de poder (ECCEL et al, 2010). Para Louro (2007), contudo, dentre as classificações envolvendo o corpo, a sexualidade tem sido a forma mais evidente de identificação dos sujeitos e, nesse sentido, é também a mais evidente forma de diferenciação social, funcionando como mantenedora da dicotomia masculino feminino (ECCEL et al, 2010). Retomamos aqui, a noção de Eccel et al (2010), de que o corpo ultrapassa a questão biológica, estabelecendo-se ainda, como um constructo social a partir de práticas que organizam os corpos, impingindo significados e estereótipos que remetem às questões gênero.

Para Eccel e Grisci (2011), o conceito inicial de gênero indica marcas culturais e acaba por estabelecer os papéis que caberiam aos homens e às mulheres. Contudo, o conceito não aborda a relação social entre os sexos, já que não evidencia as causas que perpassam as construções sexistas. De acordo com as autoras, é necessário remeter às novas concepções capazes de promover o rompimento com o binarismo masculino feminino, enfatizando os aspectos causais, como as questões de poder e as significações imbricadas nos conceitos sobre masculinidade e feminilidade. Há que se compreender que o lugar do feminino e do masculino é determinado a partir de atribuições sociais, e deve ser compreendido tanto em termos políticos quanto sociais. Essa compreensão ultrapassa as referências biológicas, e remete também às formas particulares das relações sociais.

Segundo Eccel e Grisci (2011), a discussão e torno das questões de gênero requer disposição para abordar amplamente as questões imbricadas nos sistemas de relações sociais e sexuais. As autoras apontam que questões relacionadas à gênero e identidade, muitas vezes se misturam e acabam por desconstruir e reconstruir possibilidades figurativas, culminando em uma multiplicidade de implicações que indica a inadequação de se pensar em gênero de forma binária. Assim, temos uma ampliação do conceito de gênero, sendo agora referido como uma espécie de organizador do social, para além dos sujeitos que desempenham funções masculinas ou femininas. Ao não questionar a visão dominante de masculinidade, acaba-se por consolidar o padrão masculino como uma norma, diferenciando mulheres e não permitindo a adequada observação da diversidade e das inúmeras possibilidades para viver e trabalhar.

As práticas observadas nas relações de gênero são tradicionalmente instituídas em culturas marcadas por papeis definidos a partir dos próprios gêneros. Esses papeis são a objetivação dos conceitos que demarcam as questões de gênero, caracterizando e configurando o espaço para a dominação masculina. As relações desdobradas desse cenário convergem na segregação entre masculino e feminino, firmando normas e estereótipos de uma cultura fálica, pautada em modelos ideais de masculinidade, o que de acordo com Butler (2010) forma um véu de inteligibilidade cultural em que os corpos, gêneros e desejos são entendidos de forma naturalizada, limitadora e inculcada de modelos hegemônicos. Dessa forma tem-se o estabelecimento de matrizes deterministas que ocasionam oposições assimétricas entre o masculino e o feminino (BUTLER, 2009; 2010; OLIVEIRA, 2008). A partir desses padrões de masculinidade e feminilidade, a heterossexualidade é compreendida como o natural, como aquilo que se espera de homens e mulheres. Assim, são demarcados limites estáticos entre o sexo biológico - que morfologicamente diferencia machos e fềmeas. Em sociedade, isso leva à imposição de um conjunto de regras comportamentais aceitável para o masculino e outro aceitável 
para o feminino (BUTLER, 2010; FOUCAULT, 1979).

Esse emaranhado de regras e normas sociais muitas vezes é compreendido como verdadeiros e acabam por limitar outras formas de ser que não se enquadrem nos padrões heterossexuais, impondo a homens e mulheres as formas de ser consideradas mais adequadas ao convívio social (DINIZ et al, 2013). Tudo o que estiver fora do enquadre dominante é considerado falho. Para Eccel e Grisci (2011), mesmo que o modelo da masculinidade hegemônica não esteja acessível a todos os homens, ela continua sendo apoiada e pulverizada também por aqueles que não possuem as características requeridas por esse ideal. Essa difusão continua, portanto, promovendo a manutenção dos privilégios de gênero. Contudo, as masculinidades hegemônicas não devem ser compreendidas como condições fixas, já que a própria disputa pelo poder ocasiona modificações. Nesse sentido, a produção de masculinidades hegemônicas se constitui como parte dos processos de subjetivação contemporâneos.

Contudo, o desempenho de papéis relativos ao gênero é mais claramente demarcado quando a construção de gênero é decorrente de condições punitivas. Esse aspecto pode ser observado, por exemplo, nos casos de assédio. Entretanto, vale ressaltar que a construção de identidades de gênero, não são produtos de voluntarismo radical, mas estão instituídas também, em esferas pouco compreendidas pelos sujeitos, como o inconsciente, os desejos e as pulsões (MATOS, 2000b). De acordo com Butler (2009), as identidades de gênero são construídas em meio a constrangimentos e pressões sociais, levando os sujeitos a se autovigiar e cercear suas ações no intuito de se proteger dos constrangimentos sociais. Esse enquadre social, no entanto, não se reduz a uma polaridade binária entre homens, mulheres, heterossexuais ou homossexuais, pois todos os sujeitos sofrem a incidência das relações de dominação pautadas no gênero. Mesmo os homens, comumente beneficiados pelas determinações de papeis relacionados ao gênero, embora muitas vezes, perpetuem e gozem desse sistema desigual, podem em determinadas circunstâncias sofrer os impactos negativos desse sistema pautado no ideal de masculinidade (DINIZ et al, 2013; CARRIERI et al, 2013; MENEZES et al, 2013).

As fronteiras recobertas que delimitam as identidades de gênero apresentam múltiplas dimensões, que envolvem homens e mulheres, possibilitando convergências conflituosas que impactam nas identidades de gênero (MATOS, 2000b). O imbricamento social de uma cultura fálica de gênero tem caráter estrutural, que abarca elementos normativos e normas estereotipadas. Nesse sentido, as identidades de gênero, embora coexistam, remetem a relações conflituosas, requerendo que, para compreendê-la desenvolva-se a capacidade de desvelar os signos mais sutis que remetem às formas sociais tradicionalmente estabelecidas e (MATOS, 2000b). Conforme Eccel e Grisci (2011), mesmo as masculinidades contemporâneas são continuidades de modelos anteriores, funcionam como modelos de referência, permitindo o desfrutar de uma condição tida como legitima.

São poucas as possibilidades de resistência, mas elas resultam em maneiras alternativas de existir socialmente, entretanto, não promovem necessariamente o rompimento com o sistema. São pequenas as modificações e adaptações, mas elas podem permitir criatividade e manter a existência individual a partir de princípios éticos e norteadores (ECCEL; GRISCI, 2011). É importante destacar que foi apenas no final da década de 1970, que emergiram os primeiros debates sobre o ideal de 
masculinidade e somente em meados de 1990 os estudos sobre masculinidades puderam avançar e contribuir para a desnaturalização da noção universal de homem (ECCEL; GRISCI, 2011). Ao notar a multiplicidade das masculinidades, foi lançado um olhar mais atento para os desníveis de poder entre essas mesmas masculinidades, entendidas então como não homogêneas, concentradoras de desejos e condutas contraditórias. Segundo apontam Eccel e Grisci (2011), ao observar traços de masculinidades em mulheres e traços de feminilidade em homens, contesta-se a ordem de gênero global e patriarcal, possibilitando questionamentos acerca das relações de poder e dominação dos estereótipos masculinos, que desvalorizam o diferente, demarcando o ideal de masculinidade e desqualificando tudo o que não se enquadrar nesse ideal.

No ambiente de trabalho, especificamente, a masculinidade é comumente colocada a serviço da administração, vinculando masculinidades como atributos valorizados e ligados à produtividade, à performance, ao cumprimento de metas e à competência e competitividade (MENEZES et al, 2013). Para Menezes et al (2013), a reprodução das representações e concepções de masculinidades conduzem os sujeitos ao ideal de masculinidade, colocando em oposição e desvantagem, valores mais próximos do ideal de feminilidade. Nos mais variados ambientes organizacionais, por exemplo, os traços masculinos são associados à liderança heroica $\mathrm{e}$, tanto homens quanto mulheres podem exibi-los, contudo, esses traços propriamente ditos, são compartilhados socialmente como atributos inerentes aos homens e, portanto, encarados como masculinos. O contrário ocorre em relação à feminilidade, ou seja, homens podem até apresentar traços femininos, contudo, esses mesmos traços são corriqueiramente atribuídos às mulheres e entendidos como inerentes a elas. Observando esses apontamos, pode-se inferir que para exercer o poder, hegemonicamente entendido como masculino, as mulheres e os homens precisam adotar comportamentos estereotipados e que remetem ao referencial de masculinidade (MENEZES et al, 2013).

Com base nos apontamentos realizados, buscamos investigar se os oito periódicos analisados têm suas estruturas e matérias perpassadas por esse ideal de masculinidade, bem como buscamos observar se há alguma referência à temática de gênero ou se a mesma é silenciada por esses dispositivos. A seguir apresentamos o percurso metodológico para a investigação e análise realizada.

\section{O Caminho Percorrido}

$\mathrm{O}$ presente estudo remete à tradição qualitativa de investigação que desloca os sujeitos sociais para o epicentro ontológico e epistemológico, ao contrário da tradição quantitativa que busca a vida própria das variáveis independentes da consciência humana. De acordo com Luz (2001, p. 95), esse tipo de pesquisa "compreende um conjunto de práticas interpretativas, mas não privilegia qualquer tipo de metodologia, inexistindo teoria ou paradigma que lhe seja próprio". Para Chizzotti (1991), a pesquisa qualitativa permite chegar à essência dos fenômenos estudados por meio do tratamento e interpretação dos dados, não de maneira isolada, como fatos ou acontecimentos isolados, mas sim, dentro de um contexto onde há uma dinâmica de relações. Nesse sentido, esse estudo se caracteriza pela utilização e coleta de discursos impressos (revistas de negócios) que foram analisados a partir da técnica da Análise do Discurso e da Semiótica, respectivamente. 
Buscamos construir um corpus de pesquisa composto pelas representações de masculinidades veiculadas por revistas populares especializadas em gestão, em suas imagens e textos. Segundo Corrêa et al. (2007), Cappelle et al. (2003) e Wood Júnior e Paula (2002), essas mídias apresentam-se como possibilidades de análises para a compreensão do discurso 'gerencial' e 'executivo', que afeta o que se entende e espera de homens e mulheres trabalhadores. Além das revistas especializadas em negócios, analisamos também as representações das masculinidades de executivos em revistas voltadas para o público masculino. A inclusão de tais mídias se deu, da mesma forma, por sua participação na construção dos ideais de mulheres e de homens na sociedade em que se inserem. As revistas foram a 'Exame', a 'Isto É Dinheiro', a 'Época Negócios', 'Pequenas Empresas \& Grandes Negócios', as revistas masculinas 'Playboy' e 'VIP' e as revistas femininas 'Cláudia' e 'Maire Clarie', veiculadas de março de 2009 a Outubro de 2013. A escolha por essas revistas se justificou por representarem parte significativa do mercado editorial brasileiro, tanto em termos de faturamento quanto de volume de leitores, nos respectivos ramos que atendem. Portanto, estas se constituíram locus privilegiados para se levantar os tipos de masculinidade veiculados. Cabe ressaltar que, segundo Mira (2001), as principais bases de segmentação do mercado editorial brasileiro são gênero e geração, pois, em termos de classe social, os leitores de revistas se distribuem das classes médias para cima, já que esse meio exige certo grau de familiaridade com a leitura e a existência de renda discricionária. Destacamos, ainda, que essas três dimensões estão entrelaçadas.

Para a análise das imagens coletadas nas revistas especializadas em negócios e naquelas voltadas para o público masculino, recorremos, nessa pesquisa, à Semiótica. A semiótica pode ser conceituada como a ciência que se ocupa em estudar os signos, do grego semions, tratando as possibilidades sígnicas de todas as formas de linguagem existentes, sejam elas verbais ou não. Santaella (1999, p. 2) complementa que "a semiótica é a ciência que tem por objeto de investigação todas as linguagens possíveis, ou seja, que tem por objetivo o exame dos modos de constituição de todo e qualquer fenômeno como fenômeno de produção de significação e de sentido". Isso está, assim, além de códigos verbais, e permite incluir aspectos deixados em segundo plano em estudos linguísticos, como as imagens. Para sustentar a análise semiótica das imagens encontradas, fundamentamos este trabalho em Eco (1976), autor que propõe um tratado geral sobre o campo de conhecimento, explorando as possibilidades teóricas e as funções sociais de um estudo unificado de todo e qualquer fenômeno de significação e/ou comunicação:

Um projeto de semiótica geral compreende uma Teoria dos Códigos e uma Teoria da Produção Sígnica; a segunda teoria leva em consideração um grupo muito vasto de fenômenos, tais como o uso natural das diversas linguagens, a evolução e a transformação dos códigos, a comunicação estética, os vários tipos de interação comunicativa, o uso dos signos para mencionar coisas e estados do mundo e assim por diante (ECO, 1976, p. 1, grifos nossos).

Antes, porém, cabe distinguir o conceito de semiótica da comunicação e semiótica da significação, uma vez que se recorrerá a esta última para compreender a analogia do processo de significado que assumem as 
fotografias de homens e mulheres de negócios impressas nas revistas analisadas. De acordo com Eco (1976, p. 14, grifos nossos), "a Semiótica da Significação se desenvolve a partir da teoria dos códigos, ao passo que a Semiótica da Comunicação diz respeito à teoria da produção sígnica". A teoria da produção sígnica pressupõe a função triádica da Comunicação Social emissor, mensagem e receptor; enquanto a teoria dos códigos diz respeito à interpretação sígnica de mensagens (verbais ou não) pressupondo que essas podem ser interpretadas sem a necessidade de observância da intenção do emissor. No caso da intenção editorial das revistas, esta compreensão permitiu analisar de forma independente o signo (as imagens) pronto, impresso e suas provocações e sustentações no campo hipotético do estudo. Assim, as fotografias de homens e mulheres de negócios impressas nas revistas fazem vir à luz uma interpretação sígnica confrontada com as representações sociais no mercado de trabalho no que diz respeito às questões de gênero. Observar a fotografia de um(a) executivo(a) impressa em uma revista de negócios provoca um diálogo intrínseco com o leitor e complementa sua visão estética. A imagem estática traz consigo uma série de códigos e, uma vez interpretados, tornam-se signos para o leitor. E são justamente estes signos representados nos trajes, nos acessórios e nas atitudes subliminares das fotografias que compõem o objeto da análise semiótica proposta.

Por outro lado, a função sígnica pode não se correlacionar com o conteúdo expresso nas revistas, ocasionando em uma interpretação errônea do signo. Quanto a isso, Eco (1976, p. 40) dispõe que "o mesmo elemento funtivo pode também se correlacionar com outros elementos, tornando-se assim um funtivo diferente, que dá origem a uma outra função sígnica". O caminho, então, segue na direção da relação de codificação de imagens, partindo para uma construção da função sígnica e sua correlação com o conteúdo editorial das matérias publicadas nas revistas de negócios. Nas revistas, em geral, pode-se identificar a presença do público alvo. Os signos e as representações estão dispostos intencionalmente em função de um destinatário. As representações pictóricas são concebidas para um público determinado, definido de um ponto de vista cultural, sociológico e psicológico. As linguagens icônicas do corpo, como os códigos de indumentária e os códigos de postura corporal e gestual, compõem as fotografias utilizadas nos editoriais para transmitir as diferenças entre os gêneros. As vestimentas representam um setor típico de classificação dos gêneros. As roupas são mais diferenciadas entre os gêneros na medida em que as regras sociais são mais rígidas. As calças e paletós, sobretudo escuros, seriam exclusivos dos homens; as saias e os vestidos em cores mais alegres e claras para as mulheres jovens. A aparência física, os traços masculinos e femininos podem ser mais ou menos acentuados em função desses conceitos. As posturas corporais destacam bem as expressões masculinas e femininas convencionais. Assim, os gestos mais abertos são típicos do gênero masculino enquanto as expressões mais discretas e contidas simbolizam a feminilidade.

Isto posto, surge então os pontos a serem analisados nas fotografias de homens $\mathrm{e}$ mulheres de negócios estampadas nas revistas que compõem o corpus deste estudo. Apresentam-se abaixo (figura1) os itens identificados para compor o processo metodológico:

A figura 1 apresenta um esquema do método utilizado neste estudo, mas, sobretudo, conclui o embasamento teórico. Tal esquema foi construído e sua aplicação e utilização convergem com a semiótica 


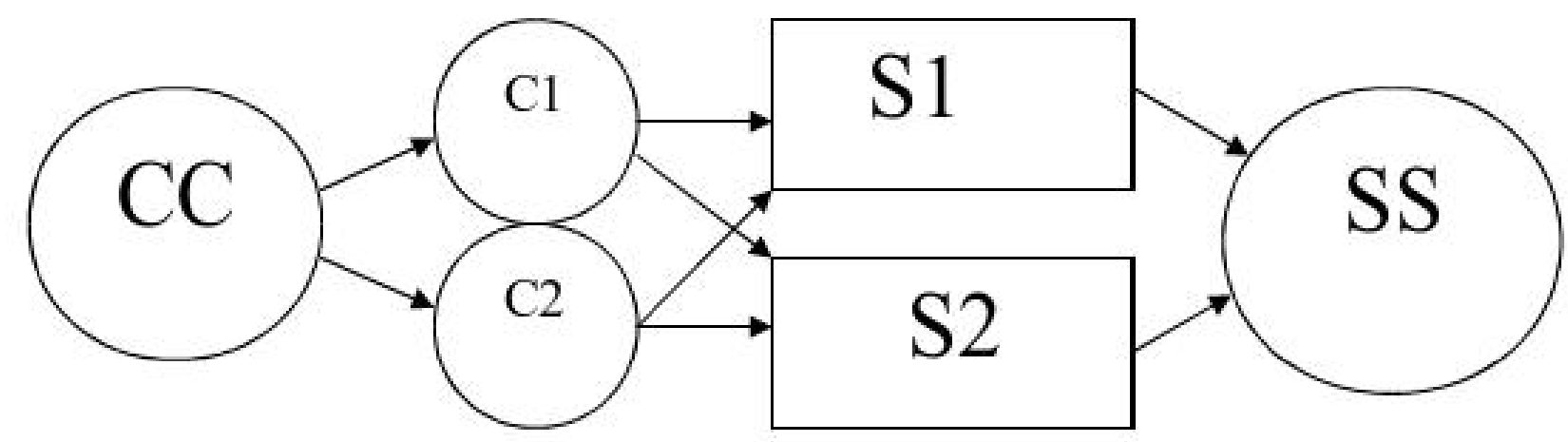

Legenda:

CC - Códigos elencados

C1 - Códigos Masculinos

$\mathrm{C} 2$ - Códigos Femininos

S1 - Signos masculinos

$\mathrm{S} 2$ - Signos femininos

SS - Função Sígnica

Fonte: Adaptado de Eco (1976).

clássica, nas releituras já publicadas, e vai ao encontro do que foi proposto por Eco (1976, p. 36), quando coloca que

ao destinatário é solicitada uma colaboração responsável. Deve ele intervir no sentido de preencher os vazios semânticos, de reduzir a multiplicidade dos sentidos, de escolher seus próprios percursos de leitura, de considerar vários ao mesmo tempo - ainda que mutuamente incompatíveis - e de reler o mesmo texto estético mais vezes, sempre controlando pressuposições contraditórias.

A seguir apresentaremos as revistas analisadas e, posteriormente, realizaremos a análise proposta, apontando os signos e as representações emergentes na mídia impressa investigada e argumentando sobre as possibilidades ignoradas por esses periódicos, que insistem em enquadrar homens e mulheres em padrões limitados e estereotipados.

\section{As Revistas Analisadas}

Conforme apresentado anteriormente, foram analisadas 8 revistas, sendo 4 identificadas como revistas de negócios (Exame, Isto É Dinheiro, Época Negócios, Pequenas Empresas \& Grandes Negócios), 2 revistas destinadas ao público feminino (Claudia e Maire Claire) e 2 dedicadas ao público masculino (Playboy e VIP). A Revista Exame é uma publicação quinzenal da Editora Abril, com tiragem de 220.300 exemplares. E $40 \%$ dos seus leitores são do sexo masculino. Do total de público desse periódico, $88 \%$ pertencem à Classe $\mathrm{A}$ ou $\mathrm{B}$ e apenas $13 \%$ podem ser situados na classe $C$. A faixa etária predominante entre os leitores está entre 20 e 44 anos. Esse público concentra-se na região sudeste e sul do Brasil. Já a Revista Isto É Dinheiro é definida, pelo corpo editorial, como a única revista semanal de economia, negócios e finanças do país, estando disponível à assinantes e também em bancas de revista em todo o Brasil. A tiragem é de 94.588 
exemplares, dos quais 75.671 (80\%) são destinados a assinantes. $62 \%$ de seus leitores são homens e a maior parte tem mais de 40 anos de idade. Como no caso da Exame, esta revista também concentra seu público nas classes A e B. A revista Época Negócios, da Editora O Globo, também apresenta público majoritariamente masculino, e a faixa etária dos leitores está entre 25 e 49 anos, provenientes em sua maioria, das classes A e B. O foco da revista é voltado para assuntos empresariais relacionados às grandes corporações. A revista Pequenas Empresas \& Grandes Negócios é um periódico mensal, definida por seu corpo editorial como uma revista de foco mais abrangente, já que visa atingir as classes A, B e C. Sua circulação é nacional e atinge uma tiragem de mais de 150 mil exemplares.

Quanto às revistas dedicadas ao público feminino, temos a Revista Cláudia, da Editora Abril, com publicações mensais e tiragem de 520.070 exemplares, dos quais 315.370 são para assinantes. $88 \%$ dos leitores são do sexo feminino, e $68 \%$ de seu público estão na Classe A ou B. A maioria, 51\%, tem entre 25 e 49 anos, e reside na região sudeste, e sul do Brasil. O corpo editorial da revista aponta que seu foco é levar possibilidades de reflexão para a mulher que desempenha múltiplos papeis. Nesse sentido, busca abordar temas como tendências, moda, família, carreira e qualidade de vida. O slogan da revista é: 'CLAUDIA é completa, como a mulher tem que ser'. A revista Marie Claire, também com publicações mensais, tem tiragem aproximada de $280 \mathrm{mil}$ exemplares. Seu editorial centra-se em beleza, moda e comportamento. Seu antigo slogan era 'Não ensina fazer renda e nem ensina a namorar', e o atual é 'Chique é ser inteligente'. $\mathrm{O}$ editorial a identifica como um periódico destinado ás mulheres maduras e independentes. $\mathrm{O}$ público predominante também é proveniente das classes A e B, das regiões sul e sudeste.

As revistas masculinas se assemelham em relação ao público alvo e foco. A VIP tem circulação média de 64.305 exemplares, os leitores são, a maioria, jovens entre 15 e 35 anos, do sexo masculino e das classes A e B, moradores do sudeste e sul brasileiros. Conforme Monteiro (2001) em suas análises sobre a VIP elucida-nos que houve uma reforma editorial com o objetivo era tornar a revista mais ágil, e mudar seu público alvo para um segmento mais jovem. A antiga VIP se dirigia aos executivos com mais de 40 anos, enquanto a "nova VIP" busca o leitor entre 25 e 45 anos, o que pressupõe um tratamento diferenciado, que vai desde reformas no visual da revista até o uso de uma linguagem mais informal. A Revista VIP é descrita por seus editores como um "guia bem-humorado para o leitor se relacionar melhor com as mulheres, aproveitar os prazeres da vida e se tornar um homem mais completo." A Revista Playboy também passou por transformações e atualmente atinge grande parte da população masculina, estando destinada especificamente a esse público e abrangendo desde matérias sobre comportamento até conteúdos de humor e moda. É um periódico permitido para indivíduos acima de 18 anos e, no Brasil, é publicado pela Editora Abril, há 29 anos, alcançando a tiragem de 153.000 exemplares.

$\mathrm{Na}$ próxima seção, realizamos alguns apontamentos e reflexões sobre o que foi encontrado em nossas análises empreendidas a partir do material coletado.

\section{Manuais de Boas Práticas ou Difusores de Estereótipos?}

\section{O mundo dos negócios}

Em anúncios de carros de marcas importadas, relógios (Rolex) e ternos de 
marcas italianas, a Revista Exame deixa claro a que veio. Ao exibir bens predominantemente destinados aos homens, gestores masculinos com renda alta, trata-se de uma revista não apenas destinada ao mundo dos negócios, mas também indicativa de como deve se portar um executivo. Ao tratar de temas como economia, gestão, administração pública e investimentos, e apontar, simultaneamente a imagem que se espera dos grandes executivos e, portanto, dos grandes homens, a revista não silencia 0 tema gênero, aliás, evidencia-o, estereotipando homens e mulheres. Quando o assunto é propositalmente abordado, predominam visões preconceituosas, tais como mulheres consumistas, vaidosas e superficiais, trabalhos tipicamente considerados femininos (aeromoças, secretárias, telefonistas) e homens executivos, diretores, chefes. As mulheres estão sempre relacionadas à moda, à televisão, e à comunicação, e seus corpos ocupam o elemento centrar da feminilidade. As mulheres que ascenderam ao poder no mundo dos negócios da Exame, pouco são representadas.

As reportagens e anúncios dessa revista trazem fotos de homens, adultos ou idosos, brancos, em posições que remetem o poder que têm - braços cruzados ou no bolso, olhar firme e para frente, leve sorriso ou nenhum. Esses homens vestem um traje condizente com o fazer-saber dos negócios, estão de terno ou de camisas de mangas compridas e transmitem a ideia de estarem sempre em movimento. $\mathrm{O}$ terno ganha destaque na Revista, como um indicativo de homem de negócio. Em um dos exemplares, escolhido aleatoriamente (janeiro de 2010), contam-se 53 homens nas ilustrações, sendo dois negros (O Presidente dos EUA, Barack Obama, e outro americano). Não aparece nenhum negro nas páginas da revista, apenas o mulato Ronaldo 'Fenômeno', jogador de futebol conhecido internacionalmente, que aparece em um anúncio. Oito mulheres aparecem na revista, três estão em situação de trabalho (uma comissária de bordo, uma pesquisadora e uma modelo). Outras duas são do meio artístico (a atriz Mariana Ximenez e a cantora americana Mariah Carrey).

Nota-se que a questão da corporeidade é recorrente na revista. Os homens são magros e a saúde do corpo está sempre estampada nas fotos. Ao executivo cabe zelar por seu corpo e saúde e a prática de esportes é frequentemente mencionada (escaladas, esqui, natação). Nota-se que o mundo dos negócios delineado pela Exame é masculino, branco, e cada vez mais jovem (até os quarenta anos). A juventude é um atributo cada vez mais valorizado no universo corporativo, como mostra a reportagem 'No topo antes dos 40', de janeiro de 2010, que traz exemplos de executivos - todos homens - que chegaram à presidência de grandes empresas brasileiras ainda 'jovens'. No ensaio desta edição, intitulado 'Eles estão abrindo caminho', a revista Exame apresentou seis empresários, entre diretores e presidentes de empresas, que tem prosperado na área de biotecnologia. Os grandes empresários que recebem destaque são em quase totalidade homens. Os executivos antes dos quarenta são considerados ousados e criativos, enquanto os mais experientes são considerados os mais indicados para lidar com a crise. É importante ainda, ressaltar que no conjunto de exemplares analisados o número de mulheres é inexpressivo ainda que na última página da revista, as mulheres têm tido voz para falar de algum assunto relevante. Embora se trate de uma publicação nacional, as brasileiras ainda disputam com estrangeiras este pequeno espaço.

Assim como a Exame, as revistas Isto é Dinheiro e Época Negócios também são voltadas ao mundo dos grandes negócios, dos grandes executivos e das grandes decisões. 
No caso da Isto É Dinheiro notou-se um projeto gráfico com cores moderadas, mantendo uma aparência conservadora e transmitindo a sensação de solidez e respeito, valores tidos como imprescindíveis entre seu publico alvo. Dentre os anunciantes, há um setor predominante que é o de carros. As empresas de Tecnologia de Informação e Comunicação também são grandes anunciantes. Merece destaque o fato de que os bens de luxo anunciados são predominantemente para homens (gestores masculinos) que ganham bem, tais como diretores e presidentes, com alto padrão de consumo e ganho econômico. As mulheres ocupam pouco espaço nos exemplares observados ( $7 \%$ das edições), enquanto os homens estampam grande parte de seus volumes. Enquanto eles figuram nas reportagens as mulheres, quando aparecem, estão em anúncios, representando papeis como atletas, mães e esposas. Raramente representam mulher de negócio. De todas as revistas a Exame parece a mais contundente em relação a um mundo dos negócios masculinizado. Além disso, o executivo remete a uma figura do sexo masculino, de porte atlético (magro) e aparência sóbria. Simultaneamente, as mulheres, quando aparecem, têm sua imagem corroborando categorias coadjuvantes do mundo masculino.

Se na Exame o tema gênero aparece de forma sutil, na Isto É Dinheiro o tema é quase totalmente silenciado, ocupando um espaço mínimo na publicação. A figura feminina não é frequente e quando surge remete à indústria da moda, televisão e o corpo também é elemento central da feminilidade. A revista é hegemonicamente masculina e os homens de negócios estão quase sempre posando para as fotos, mesmo que não estejam, necessariamente, figurando uma situação de trabalho. Quando aparece uma mulher figurando como diretora de uma empresa importante, o fato é tratado como algo não convencional. Abaixo temos duas ilustrações de capa da referida revista:

Figura 2 - Capas Revista Isto É Dinheiro.
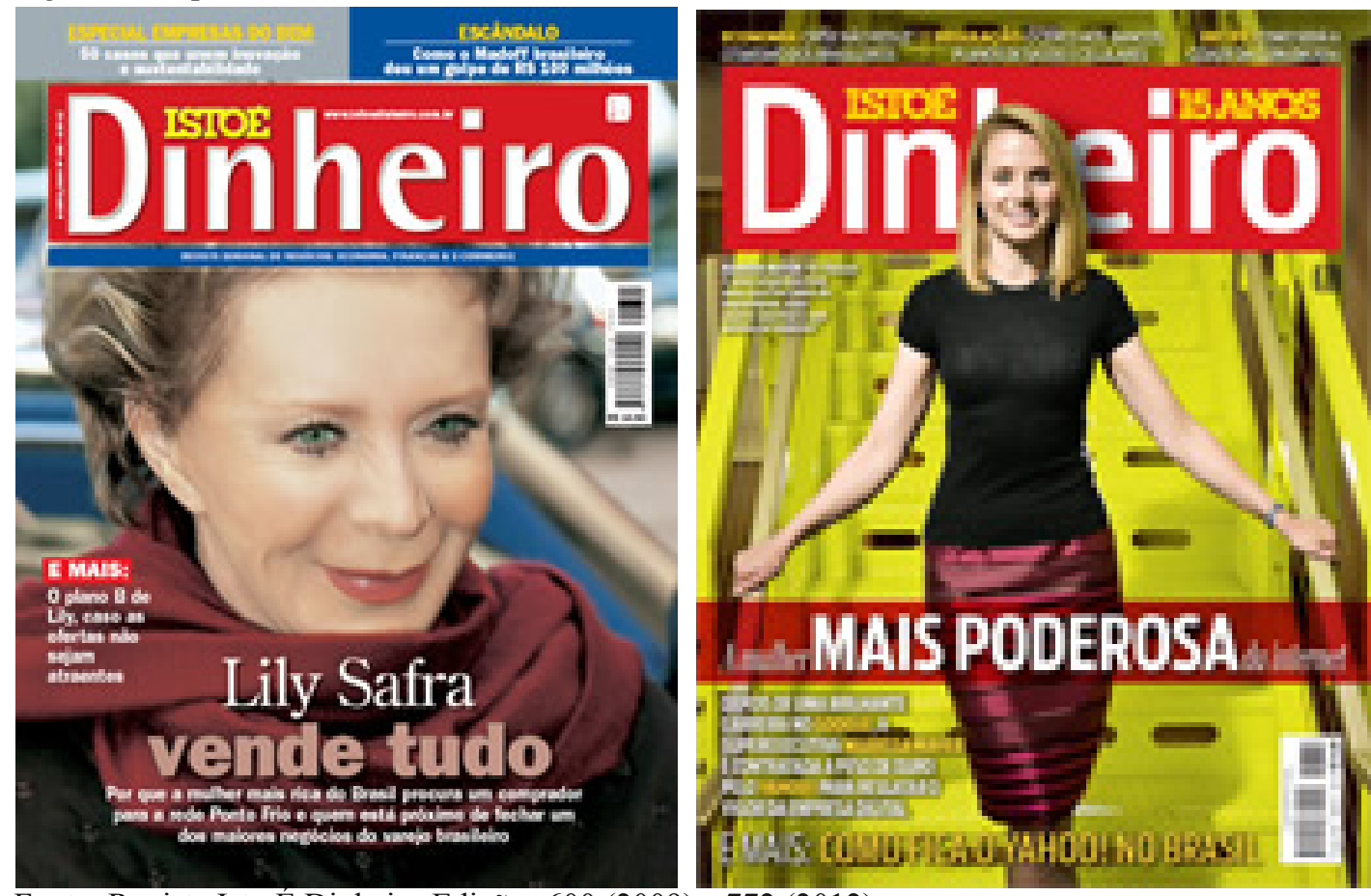

Fonte: Revista Isto É Dinheiro Edições 600 (2009) e 772 (2012). 
As manchetes corroboram com a ideia de que as mulheres "já" são maioria entre os empreendedores brasileiros, entretanto, deixam no ar, que embora poderosas, continuam tendo atitudes esperadas para as mulheres. Tanto nas revistas Exame e Isto É Dinheiro, quanto na Época Negócios o papel das mulheres é tido como secundário, mas especificamente na última, a maior parte das mulheres que fizeram parte das edições analisadas são acadêmicas, especialmente na área de desenvolvimento genético, da biotecnologia (setor amplamente divulgado pela revista). Em termos gerais, as mulheres que figuram essas revistas são brancas e têm mais de 50. Quando retratadas, as mulheres jovens ocupam papel ainda mais insignificante e, mesmo em meio a textos que clamam pelo reconhecimento da importância da mulher nas organizações, predominam crenças sexistas e as gestoras são comumente lembradas por alguma forma de lapso ou mesmo fracasso em sua gestão, o que sutilmente ou são, é atribuído ao seu gênero e não à sua capacidade técnica. A Revista Isto É Dinheiro, por exemplo, aponta que a partir da crise econômica o papel da mulher foi aumentado, mas os salários pagos às mulheres ainda são menores que os pagos aos homens. Outro destaque é que as mulheres costumam ocupar as hierarquias intermediárias. Esse aspecto corrobora o fato de haver carreiras e ocupações ainda predominantemente masculinas, mesmo com o avanço da entrada de mulheres nas áreas. Outro importante aspecto a ser destacado é a disparidade entre os salários, que só diminuem quando é reduzido o salário dos homens (ORGANIZAÇÃO INTERNACIONAL DO TRABALHO, 2013).

Complementarmente, a revista Pequenas Empresas Grandes Negócios também evidencia os distanciamentos e disparidades entre gêneros no mundo dos negócios. Embora se trata de um veículo em que as mulheres estão representadas mais frequentemente do que nos anteriormente citados, a figura do homem é sempre mais expressiva, com fotografias mais contundentes, de meio corpo ou corpo inteiro e ocupando as páginas por completo. É importante ressaltar que se trata de um dispositivo que visa estimular o empreendedorismo tanto para homens como para as mulheres, entretanto, fica clara a tendência da revista em rotular essa ou aquela atividade como mais adequada a homens ou mulheres. O mais comum é observar fotos em que o empreendedor é representado como uma pessoa jovem (menos de 40 anos), com formação universitária começando pequenos negócios. Entre os exemplares analisados, o número de abril de 2009 traz à tona um elemento passível de ser pensado sob a perspectiva de gênero, em que discute as características femininas que favorecem a mulher na cena empresarial. A chamada fala sobre o que aprender com as mulheres empreendedoras e seu jeito particularmente feminino de tocar seus negócios. Dados interessantes são apontados, como o fato do Brasil ocupar o sétimo país, no cenário global, com mulheres empreendedoras, onde franquias geridas por mulheres chegam a faturar $32 \%$ a mais do que as comandadas por homens. De acordo com a reportagem, as mulheres destacam-se nos setores da arquitetura, vestuário, alimentos e cosméticos, o que nos permite fazer uma analogia às atividades tradicionalmente desempenhadas pelas mulheres, como os cuidados com a casa, com as roupas e com a alimentação.

Ainda na referida matéria um comentário registrado como sendo de uma empreendedora é incisivo, pois corrobora com a crença de que as mulheres, para destacarem-se precisam adotar comportamentos considerados inerentes ao homem como praticidade, menos impulsividade e capacidade de planejar. 
Outra matéria, presente no exemplar de julho de 2010 retrata essa crença, já que Patrícia Amorim, presidente do Clube de Futebol do Flamengo, aparece vestida com uma camisa branca e apresentada pelos dizeres: 'Ela quer sanear as finanças do clube e transformá-lo em um modelo de gestão'. Ao analisar esse dizer a partir da semiótica greimasiana, sob um plano de conteúdo com percurso gerativo de sentido, observa-se uma linguagem que vai do nível mais simples e abstrato (fundamental) ao mais complexo e concreto (discursivo) sem, contudo, deixar de pincelar o nível intermediário (narrativo). A Partir do nível fundamental, em que as categorias semânticas de base são as que sustentam o texto, considerou-se a oposição Vida X Morte como uma categoria semântica de base, já que tínhamos um time em situação precária de gestão e precisava ser slavo pela nova gestora. Essa oposição implica dois termos contrários, gerando contraditos a partir da negação não vida e não morte. Nota-se que tratam-se de questões complementares em que o movimento morte para não morte, revela vida, proporcionada pela nova presidente do time.

No nível narrativo o sujeito (Flamengo) entra em junção com o objeto-valor (gestão) a partir da ação de um segundo sujeito (Patrícia Amorim), que concretiza o movimento. $\mathrm{O}$ terceiro nível (discursivo) traz as categorias que ancoram o texto a uma situação comunicativa, em que a transformação, apontada pela revista como a 'hora da virada', é sinônimo do tema vitória por um novo modelo de gestão, o que se opõe à derrota, sinônimo de má gestão. O plano de expressão do texto, observado pela dimensão fotocromática (primeira página de fundo preto sobreposta de uma segunda página com blusa na cor branca) evidencia oposições como sombra X luz, homologando à categoria semântica de base, vida $\mathrm{X}$ morte. Nas demais imagens observadas nos exemplares, as fotos são simétricas (mesmo número de homens e mulheres) e muitas reportagens são proporcionais ao tamanho das fotos, que em geral, apresentam movimento por parte dos trabalhadores.

\section{Morte}

\section{Vida}

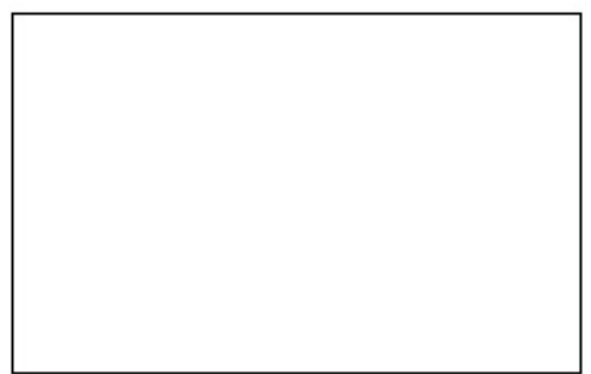

Não-vida

Não-morte

Fonte: Elaborado pelos autores. 
Figura 4: Imagens de empreendedores ilustrados pela revista Pequenas Empresas Grandes Negócios.
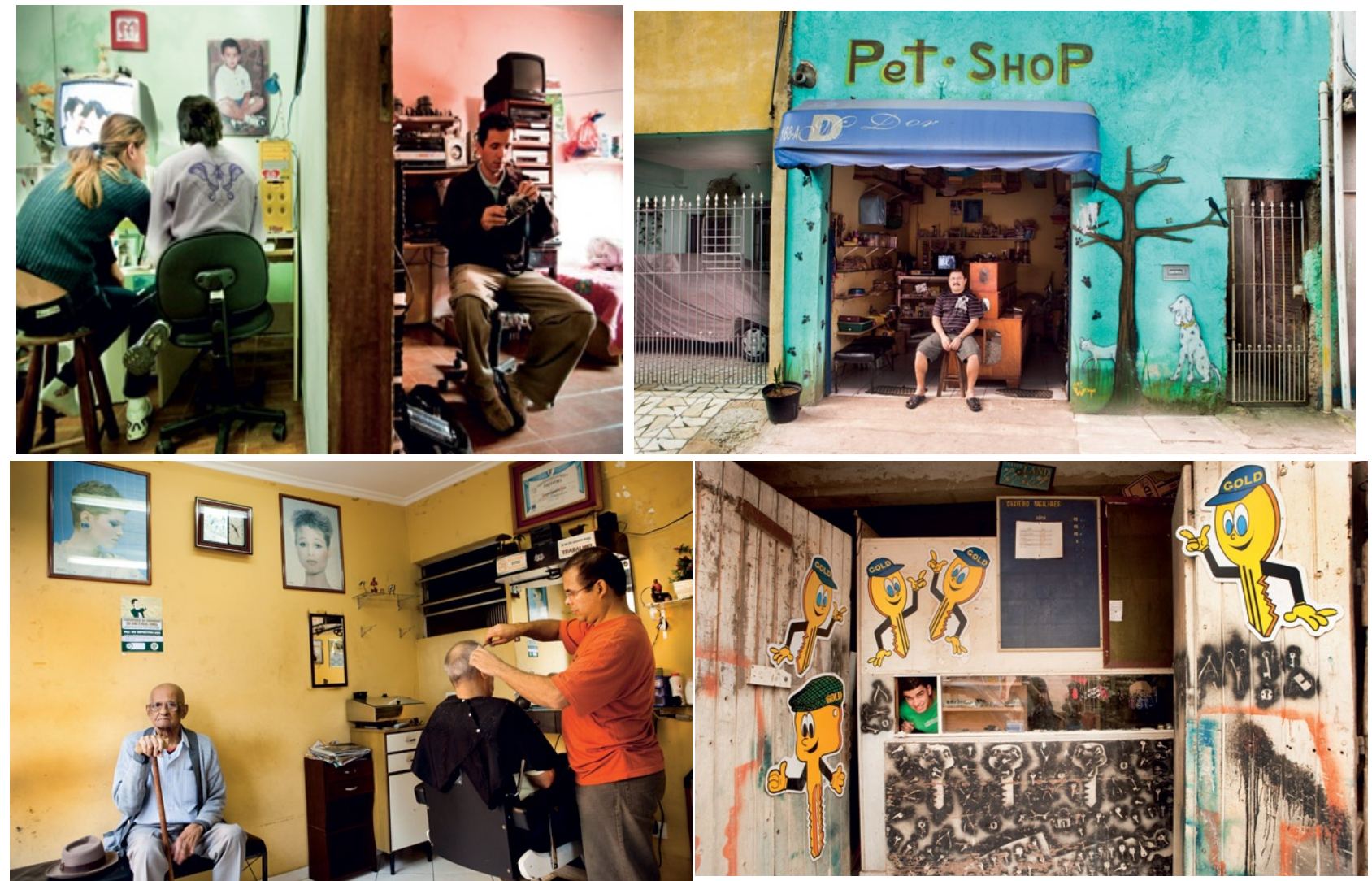

Fonte: Revista Pequenas Empresas Grandes Negócios, Edição 258 - Julho (2010).

Nota-se ainda, a simplicidade das imagens apresentadas pelo periódico, bem como a referência indireta ao empreendedorismo por necessidade, em que os negócios empreendidos são a única fonte de renda para o sustento da família. Trata-se de empreendimentos tocados por homens e mulheres provenientes de favelas e atribui a esses personagens o status de pessoas felizes, não há qualquer menção às dificuldades enfrentadas por esses empreendedores. Ainda no sentido de caracterizar os diversos tipos de empreendedores, a edição de março de 2010 retoma o assunto apontando que no caso das franquias, $41 \%$ dos novos empreendimentos são gerenciados por mulheres e que são mais lucrativos nas mãos delas, embora não exista menção a um modelo de gestão feminino.
Buscando compreender um pouco a disseminação dos ideais que perpassam essas revistas de gestão, analisamos ainda, dois periódicos destinados ao universo feminino que tipo de crenças são disseminadas, bem como os valores que esse tipo de mídia tenta retificar e difundir ao seu público. Nesse sentido, apresentamos a seguir, uma breve análise sobre duas revistas destinadas ao público feminino.

\section{Universo feminino?}

Para Buitoni (1990), a imprensa voltada ao público feminino exagera em aconselhamentos, fazendo disso uma espécie de estratégia de persuasão, já que traz textos assinados por especialistas, com o intuito de ensinar. Comumente esses ensinamentos têm 
uma roupagem impositiva, de uma ordem, pautada em uma espécie de autorização científica, que traduz ou dissimula discursos autoritários, sob o pretexto de informar - já que a mulher não sabe. É nesse sentido que a revista Claudia ressalta a multiplicidade dos papeis femininos, oferecendo dicas e soluções para a mulher que lida com tantas atribuições. Trata-se de um senso ou consenso sobre o que tem que ser, ou seja, sobre uma realidade que não precisa ser modificada, já que cabe mesmo à mulher certos papeis. Os exemplares dessa revista são distribuídos, mensalmente, à cerca de 500 mil brasileiros e bordam assuntos como emagrecimento, saúde e beleza, com artigos voltados às mulheres de 20,30, 40, 50 ou mais anos de idade. Esse aspecto evidencia que a preocupação com certos assuntos devem começar cada vez mais cedo e seguir por toda a vida feminina, corroborando a ideia de que a juventude é realmente, o principal elemento de imaginário moderno (FREITAS, 2000). Os anúncios e matérias observados em nossa investigação, principalmente os que tratam do tema mulher e trabalho, revelaram que o principal elemento da imagem é a juventude. Os anúncios trazem itens como panelas e cosméticos.

As estratégias de persuasão enunciativas estão presentes nas matérias e nos anúncios e são sempre muito contundentes, mesmo quanto aparentemente sutis. Temas relevantes são tratados, tais como a violência contra a mulher e as leis de proteção e o aborto. Em uma matéria de março de 2009, que trata de apresentar uma mulher em evidência no mundo da política, a revista traz uma de suas falas que diz haver certa dificuldade em ser mulher e lidar com a mídia, já que no Brasil, 'Na vida pública, a mulher tem de ser dura'. Essa afirmativa se refere a algo recorrente no país, em que os comentários em torno da vida pública de uma mulher costumam ser atrelados à superficialidade, o que corrompe qualquer forma de representação justa $\mathrm{e}$ acarreta na desatenção aos aspectos profissionais, privilegiando conteúdos da vida pessoal ou da aparência física das mulheres. Esse aspecto é evidenciado em uma matéria no exemplar de julho de 2009, em afirma-se que o sucesso profissional atrapalha a vida sentimental das mulheres. $\mathrm{O}$ conteúdo está fundado em uma pesquisa que aponta que apenas $20 \%$ das executivas das 500 maiores empresas constantes no Guia Exame são casadas, ao contrário dos homens, que ocupam a margem dos $80 \%$. O texto faz referencias a uma perda da lógica tradicional das famílias e apontam a situação dessas mulheres como dramáticas, já que lhes atribuem a escolha entre a profissão e a vida amorosa. Esse aspecto pode ser entendido pelos leitores como um limitador da ascensão das mulheres no mundo do trabalho, e acrescentam que isso se soma às características físicas, levando as mulheres a se degenerificar e cumprir suas atividades profissionais como se fossem homens, impedindo que suas características femininas venham atrapalhar seu desempenho. Nesse sentido, atribui-se a feminilidade ao mundo externo ao trabalho, ou então, emparelham a temática da sedução para descaracterizar ou menosprezar a competência de uma mulher, atribuindo seus ganhos e avanços à sensualidade e sexualidade.

Nota-se que o poder é algo implicitamente atrelado ao mundo masculino, capaz de garantir respeito (em oposição ao mundo degenerado das mulheres). $\mathrm{O}$ tema da sensualidade é comumente referenciado para evocar, metaforicamente explicações para determinadas circunstâncias da vida profissional das mulheres. Ou ainda, recorrese à oposição entre suavidade (feminina) e brutalidade (masculina), reforçando a subordinação das mulheres aos homens no mundo corporativo, assim como no universo 
social e particular. Ao analisar os exemplares da revista Maire Claire observamos reportagens sobre sociedade e seus costumes, que incidem sobre a sensualidade atribuída às mulheres. Colocam mulheres separadas aos 30 anos de idade como diferentes (desviantes) e costumam recorrer à temáticas ligadas à relacionamentos, depressão, doença em família, violência sexual, bulimia e drogas.

Ainda ganham espaços as dicas culturais e gastronômicas, e também turismo. Cerca de $58 \%$ dos exemplares abordam algo relacionado à cena afetiva, e aproximadamente $40 \%$ tratam de assuntos relacionados à sexualidade masculina. Tais matérias tem o intuito de esclarecer à mulher, peculiaridades do comportamento masculino. Há a predominância de anúncios de cosméticos, e o apelo pelo rejuvenescimento é presente de forma incisiva. Existem ainda, anúncios de moda, como vestuário, calçados e acessórios. Itens de alimentação e produtos de higiene ocupam cerca de $5 \%$ dos anúncios. É comum ver a imagem da mulher relacionada à imagens de crianças, em anúncios de fraldas, e outros utensílios para criança, ou mesmo em promoções de pacotes turísticos. A média das mulheres que figuram esses anúncios aparenta estar na faixa dos 20 anos de idade, são, em sua maioria, brancas, têm corpos esbeltos, peles sem imperfeições e cabelos longos. É raro observar uma mulher negra e, quando acontece, se trata de alguém já conhecida do grande público, como atrizes que atuam em programas atuais. Apenas um anunciante utiliza a imagem de mulheres com mais de 40 anos, entretanto, suas campanhas costumam pregar 0 caráter antienvelhecimento. Nota-se uma idiossincrasia nesse ponto, visto que as imagens das mulheres nas revistar fazem alusão a uma eterna juventude, enquanto as leitoras do periódico são mulheres mais velhas. Há que se apontar ainda, que o ponto mais evidente nesses periódicos é a constante referência aos padrões estéticos.

Quando se remete à imagem do homem, esta está relacionada à capacidade de sedução da mulher, em que o homem é um vouyer. Observa-se ainda que, a revista Maire Claire recorre a elementos lúdicos $\mathrm{e}$ às vezes superficiais, em que o objetivo de insuflar o consumo parece suprir o papel da difusão de informações relevantes, restringindo o universo feminino as questões ligadas à moda, beleza, comportamento e sexo (KEIN; RAMOS, 2005). É comum as matérias apresentarem um tom de manual, com regras que reforçam a visão conservadora sobre o papel da mulher, estimulando relações de submissão, pontuando o sexo como moeda de troca. A mulher servil e sedutora é retratada com frequência em um elevado número de matérias que sugerem subserviência diante do sexo masculino. O valor da mulher é comumente relacionado à capacidade cuidadora da mulher e as relações de trabalho, o cotidiano da mulher executiva são relacionados a temas como generosidade, responsabilidade social e ações beneficentes. Historias de mulheres em torno de suas ações sociais são usadas como fonte de inspiração àqueles que ainda não praticam tais ações. Se esses assuntos são relacionados ao universo feminino, quais seriam os principais assuntos abordados nas revistas destinadas ao público masculino? Nesse sentido, apresentamos a seguir, algumas impressões emergidas a partir das análises de duas revistas destinadas a esse público, conforme apresentamos a seguir.

\section{Coisas de menino}

A primeira revista analisada foi a VIP, publicada há 22 anos, sendo encarte especial da revista Exame por 13 anos. A VIP se propõe como uma revista cuja proposta é oferecer ao público masculino heterossexual 
pautas que incluem sexo e mulheres (MONTEIRO, 2001). Ao analisar os exemplares de Julho de 2009 a Outubro de 2013, pudemos confirmar que o público alvo é bem definido e as matérias, fotos e publicidade contidas nas revistas são claramente direcionados a esse público. A seção 'Preliminares' traz noticias sobre esportes, atrizes e mulheres de destaque entre o grande público. A seção 'Boa Vida' fala sobre comidas, lugares, bebidas e experiências. Já a 'Estilo Vip' traz conteúdo de moda masculina e cuidados com o corpo. Em 'Corpo e Mente' o tema da saúde masculina é o ponto central. A seção 'Cabeça' fala sobre cultura e a seção 'Sempre' trata de assuntos mais diversificados, mas comumente recai sobre temas sexuais. Cerca de $50 \%$ das páginas apresenta propagandas que incluem moda masculina (casual, praia e piscina), produtos como relógios, perfumes e sapatos, celulares, carros e bicicletas e outros materiais esportivos. Propagandas de futebol (campeonatos regionais e nacionais) também compõem o mix de ofertas publicitárias.

A revista não faz menção ao mundo profissional feminino ou mesmo as carreiras de mulheres que não sejam atrizes ou musas populares. As matérias que falam sobre mulher remetem ao sexo e orienta os homens em relação aos comportamentos que devem ser adotados em suas relações com as mulheres. Fantasias sexuais e ensaios fotográficos provocantes são material fundamental da revista, que também traz conteúdos sobre as opções noturnas de lazer e entretenimento. As imagens das mulheres trazidas nas edições da revista são em sua maioria de mulheres jovens, magras e brancas, comumente em posições de cunho sexual. No exemplar do mês de maio de 2010 há uma reportagem sobre carreira profissional que traz quatro homens que se tornarão presidentes das companhias em que atuam, um deles tem menos de 35 anos.
O papel da mulher é delineado desde a capa até as reportagens, propagandas e fotos que ilustram a revista. As mulheres são geralmente representadas como detentoras de uma personalidade generalizada e em posição oposta ao homem. A mulher é apresentada como objeto de desejo, algo a ser conquistado. $\mathrm{O}$ estereótipo da mulher perfeita é fortalecido pela revista, especialmente ao apontar os padrões de beleza. A diversidade feminina não é representada na revista que traz mulheres, em sua maioria, loiras e jovens. Nenhuma em Quando em situação de trabalho, a mulher é apresentada de maneira a representar uma fantasia sexual.

A segunda revista masculina que analisamos foi a Playboy. Periódico dividido em 'Ensaios', 'Reportagens', 'Entre Nós', 'Playboy Responde', 'Entrevistas', 'Grandes Vultos', 'Estilo do Playmen', 'Piadas da Playboy' e 'Estilo'. O público alvo pertence às classes mais abastadas economicamente e as grifes de valores mais altos são evidenciadas nas edições. Práticas corporais como atletismo ou musculação são comumente mencionadas, e o estilo de vida esportivo é valorizado nas reportagens, como indicativo de saúde e beleza. Os corpos esbeltos são supervalorizados, seja em relação aos homens ou mulheres que aparecem nas matérias ou anúncios. Embora com foco aparentemente diferente, as revistas Exame e Playboy são destinadas ao mesmo público, sujeitos masculinos, heterossexuais e com bom poder aquisitivo. Os anúncios não apenas são semelhantes como, muitas vezes, são os mesmos em ambas. Há nesses periódicos um ideal de homem, de uma elite do mundo dos negócios. $\mathrm{O}$ administrador ordinário não interessa, mas sim o grande executivo, aquele com o glamour na medida dos sonhos dos seus leitores, brancos, bem sucedidos e heterossexuais, de uma masculinidade específica, com tônus necessário as elites executivas. Uma 
masculinidade excludente, em que as diversidades de comportamento são consideradas desviantes e, portanto, desvalorizadas.

\section{Conclusão}

Não pretendemos aqui, apontar responsáveis pela disseminação ou pela conservação das práticas discriminatórias, mas observamos nessa pesquisa que os estereótipos de masculinidade e feminilidade seguem sendo pulverizados em meio a nossa sociedade. Crenças e valores distorcidos são conteúdos recorrentes entre os manuais de sucesso para homens e mulheres. Fundamentos preconceituosos e equívocos recorrentes seguem naturalizando o que não é natural e atribui a homem e mulheres papéis que os aprisionam em lugares demarcados, promovendo a exclusão e demarcação de espaços distintos para homens e mulheres. $\mathrm{O}$ julgamento do que é permitido ou não ao homem e à mulher fica evidente nas mais variadas matérias expostas nas revistas analisadas. $\mathrm{O}$ modelo masculino não cabe à mulher e as desigualdades da vida particular parece se estender ao mundo corporativo, seja no que se refere às relações de trabalho e valorização dos profisssionais ou mesmo nas relações de consumo. $\mathrm{O}$ patriarcado, apontado por Pateman (1993), segue firme em seu lugar de destaque.

A divisão da cena social entre masculino e feminino, bem como as representações difundidas pelas revistas analisadas estimulam e retificam as práticas sociais, num movimento vicioso, em que o leitor segue digerindo as informações obtidas e procurando por mais informações que corroborem as crenças inicialmente fomentadas. Os ideais de masculinidade e feminilidade representados nas revistas contribuem para que homens e mulheres se posicionem conforme um determinismo conservador e excludente, pautado por elementos que valorizam a virilidade em detrimento da feminilidade. $\mathrm{O}$ mundo dos negócios, por exemplo, segue pertencendo ao que é masculino, e a "cozinha", segue como o lugar de conforto para o feminino. Essas construções ideológicas perpassam a sociedade insuflando as diferenças e direitos são cerceados em nome de uma ordem dita natural, onde aqueles que não se enquadram são marginalizados.

A interpretação política dos corpos biologicamente diferenciados não leva em conta o fato de que o corpo não é um simples depositário de gênero, mas ultrapassa as questões físicas para construir dinâmicas sociais constantemente alimentadas no imaginário social. Os periódicos analisados nos mostraram que suas propostas não são diferentes quando o assunto é o papel ocupado por homem ou mulher. Os discursos disseminados reproduzem o ideário popular e traduz, em aconselhamentos, o caráter separatista das relações de gênero. A condução a essa ou aquela forma de ação ou de pensar apenas simulam a ordem que se espera promover na sociedade, indicando aos indivíduos, por meio de roteiros e receitas, como se deve agir, de acordo com seu papel na sociedade, o papel de homem e o papel de mulher.

Realizar pesquisas, nesse sentido, é uma forma de desvelar as sutilezas que seguem demarcando os espaços e excluindo os indivíduos. Discutir sobre a problemática de gênero, pautando-se em discursos largamente disseminados em nossa sociedade é uma tentativa de provocar discussões em torno dos perigos suaves, que levam a pecha de entretenimento, mas que são nada menos que inculcações perigosas e, por que não dizer, violentas e cruéis para com aqueles que não atendem aos clamores estereotipados. Mais do que produzir conhecimento acadêmico, pesquisas nesse sentido se fazem necessárias 
para promover o desconforto, o descontentamento e a inquietude perante formatações tão excludentes e execráveis. Os mais diversos seguimentos da sociedade revelam a disparidade entre os direitos de homens e mulheres e é por isso que consideramos importante que investigações acadêmicas sejam recorrentes em torno dos mais variados objetos, sejam eles relacionados à mídia, às relações de trabalho ou às organizações.

\section{Referências}

BOURDIEU, P. A dominação masculina. 5 ed. Rio de Janeiro: Bertrand Brasil, 2007.

BUITONI, D. S. Imprensa feminina. 2 ed. São Paulo: Editora Ática, 1990.

BUTLER, Judith. Regulaciones de gênero. Revista de estúdios de gênero - La ventana, n. 23, p. 7-35, 2006

BUTLER, Judith. Performatividad, precariedad y políticas sexuales. Trad. Sergio López Martínez. AIBR. v. 4, n. 3, p. 321-336, 2009.

BUTLER, Judith. Problemas de gênero: feminismo e subversão da identidade. 3 ed. Rio de Janeiro: Civilização Brasileira, 2010.

CAPPELlE, M. C. A; MAGESTE, G. S.; MELLO, M. C. O. L.; BRITO, M. J. M. A Representação Feminina na Mídia de Negócios: um Estudo com Duas Revistas Populares Especializadas em Gestão. ENANPAD, 27, 2003. Atibaia, Anais... [S.I.]: 2003. CD-ROM.

CARRIERI, A. de P.; DINIZ, A. P. R.; SOUZA, E. M.; MENEZES, R. R. S. Gender and work: representations of femininities and masculinities in the view of women brazilian executives. In: Brazilian Adminitration Review, Rio de Janeiro, v. 10, n. 3, art. 3, pp. 281-303, July/Sept. 2013a.

CARRIERI, A. P.; AGUIAR, A. R. C.; DINIZ, A. P. R. Reflexões sobre o indivíduo desejante e o sofrimento no trabalho: o assédio moral, a violência simbólica e o movimento homossexual. Cadernos Ebape, v. 11, n. 1, p. 165-180, 2013 b.

CHIZZOTTI, A. Pesquisa em Ciências Humanas e Sociais. São Paulo: Cortez, 1991.

SARAIVA, E. V. A construção de estratégias: um estudo de caso no setor de telefonia móvel. Dissertação (Mestrado em Administração) - Centro de Pós-Graduação e Pesquisa em Administração/CEPEAD, Faculdade de Ciências Econômicas, Universidade Federal de Minas Gerais, Belo Horizonte, 2004.

CORRÊA, A. M. H.; GONTIJO, M. C. L.; ASSIS, L. B.; CARRIERI, A. p. ; MELO, M. C. O. L. Soldadinhos-de-chumbo e Bonecas: representações sociais do masculino e feminino em jornais de empresas. Revista de Administração Contemporânea, v. 11, p. 191-211, 2007.

DINIZ, A. P. R.; CARRIERI, A. P.; GANDRA, G.; BICALHO, R. A. Políticas de diversidade nas organizações: as relações de trabalho comentadas por trabalhadores homossexuais. Revista Economia e Gestão, v. 13, n. 31, p. 93-114, 2013.

ECCEL, C. S.; GRISCI, C. L. I.; TONON, L. Representações do corpo emu ma revista de negócios. Psicologia e Sociedade, v. 22, n. 2, p. 309-317, 2010.

ECCEL, C. S.; GRISCI, C. L. I. Trabalho e 
gênero: a produção de masculinidades na perspectiva de homens e mulheres. Cadernos Ebape, v. 1, n. 9, p. 57-78, 2011.

ECO, U. Tratado geral da semiótica. São Paulo: Perspectiva, 1976.

FREITAS, M. E. Contexto social e imaginário organizacional moderno. Revista de Administração de Empresas, v. 40, n. 2, p. 6-15, 2000.

FOUCAULT, M. História da sexualidade I: a vontade de saber. 2. ed. Rio de Janeiro: Graal, 1979.

HASSARD, J.; HOLLYDAY, R.; WILLMOT, H. Introduction: the body and organization. In: HASSARD, J.; HOLLYDAY, R.; WILLMOT, H Bodies and organization. London, Thousand Oaks, New Delhi: Sage Publications, 2000.

KLEIN, J. J.; RAMOS, F. B. Revistas femininas: construindo a imagem da mulherleitora. In: II Colóquio Leitura e Cognição, 2005, Santa Cruz do Sul. Anais ... 2005.

LOURO, G. L. Gênero, sexualidade e educação: uma perspectiva pósestruturalista. Petrópolis: Vozes, 1997.

LOURO, G. L. Pedagogias da sexualidade. In: LOURO, G. L. (Org.). O corpo educado. Belo Horizonte: Autêntica, 2007, p. 7-34.

LUZ, T. R. Telemar - Minas: competências que marcam a diferença. 2001. 307f. Tese (Tese de Doutorado em Administração) Universidade Federal de Minas Gerais, Belo Horizonte, 2001.

MATOS, M. Dimensões da Masculinidade no Brasil: uma discussão conceitual preliminar. In: I Simpósio Internacional O Desafio da
Diferença: articulando Gênero, Raça e Classe, 2000b, Salvador. v. 1. Anais... 2000a.

MATOS, M. Reinvenções do Vínculo Amoroso: cultura e identidade de gênero na modernidade tardia. 1. ed. Belo Horizonte: Editora UFMG, 2000b.

MATOS, M. Dimensões da Masculinidade "à brasileira". Rio de Janeiro: Fundação MacArthut e Fundação Carlos Chagas, 2001a. (Relatório final de pesquisa, Projeto 45, PRODIR III - "Homens/ Masculinidades").

MATOS, M. Tradição e destradicionalização nas masculinidades brasileiras: transformações na sexualidade, erotismo e corporalidade masculinas de gênero. In: III Encontro Enfoques Feministas e as Tradições Disciplinares nas Ciências e na Academia, 2001, Niterói. Livro de Resumos, 2001b. v. 1. p. 122-123.

MENEZES, R. S. S.; OLIVEIRA, J. L.; DINIZ, A. P. R. Simbolismos de gênero e gestão: uma análise das feminilidades de executivas brasileiras. Revista de Gestão e Secretariado, v. 4, n. 1, p. 01-22, 2013.

MIRA, M. C. O leitor e a banca de revista: a segmentação da cultura no século XX. São Paulo: Olho d'Água/FAPESP, 2001.

MONTEIRO, M. Revistas masculinas e pluralização da masculinidade entre os anos 1960 e 1990. Revista Lugar Comum, no 12. 2001.

OLIVEIRA, P. P. A construção social da masculinidade. Rio de Janeiro: IUPERJ, 2004.

OLIVEIRA, A. V. A teoria de Judith Butler: implicações nas estratégias de luta no 
É para menino ou para menina? Representações de masculinidade e feminilidade

movimento feminista. II Seminário Nacional. Anais... Salvador, 2008.

ORGANIZAÇÃO INTERNACIONAL DO TRABALHO. Relatório Global sobre os Salários 2012/13: salários e crescimento equitativo. Genebra, 2013.

PATEMAN, C. O Contrato Sexual. Rio de Janeiro: Paz e Terra, 1993.

SANTAELLA, L. O que é semiótica. São Paulo: Brasiliense, 1999.

SCOTT, J. Gênero: uma categoria útil para a análise histórica. Recife: SOS Corpo, 1995.

WOOD JR, T.; PAUlA, A. P. P. Popmanagement: pesquisa sobre as revistas populares de gestão no Brasil. In: ENANPAD, 26, 2002. Salvador, Anais... [S.I.]: 2002. CD-ROM. 